\title{
PRÁTICA DE TEXTO E ARGUMENTAÇÃO
}

\author{
Iara Bemquerer Costa*
}

\section{Algumas razões para o trabalho com a argumentação}

Nos estudos de lingüística textual é consensual o reconhecimento de que a coerência, mais do que a coesão, é a condição mínima necessária para a constituição de um texto. A propriedade nuclear do texto seria a coerência definida por Fávero (1991) como "os modos como os componentes do universo textual, isto $E$, os conceitos e as relaçōes subjacentes ao texto de superfície, se unem numa configuração, de maneira reciprocamente acessível e relevante ${ }^{n}$. As características da coerência (seu caráter nuclear na constituição do texto e subjacente à superfície textual) apontam para a importância da inclusão de seu estudo como um dos itens essenciais na prática de produção/recepção de textos; indicam também a necessidade de uma abordagem pedagógica do texto centrada

* Universidade Federal do Paraná p. 10 .

1 FÁVERO, Leonor Lopes. Coesão e Coerência Textuais. São Paulo : Ática, 1991, 
nos esquemas macrotextuais, mais do que na sistematização de características superficiais, microtextuais.

Dentro dessa perspectiva, pretende-se, neste artigo, dar algumas indicaçōes para um possivel trabalho com a coerência em um tipo específico de texto: o argumentativo. A proposta de trabalho apresentada corresponde ao conjunto de atividades de prática de leitura e produção de texto apresentadas em material didático ora em teste na UFPR. ${ }^{2}$ Embora esse material tenha sido elaborado visando um grupo específico de usuários - alunos de cursos avançados de produção/recepção de textos - os princípios apresentados podem, em tese, ser adotados em outros níveis de ensino.

No trabalho pedagógico com textos, é interessante ter-se sempre no horizonte, como um referencial para toda e qualquer atividade, que o texto é resultante de um processo de interação entre indivíduos (um autor e um leitor), dentro de uma situação definida, e gravita em tomo de um assunto único, que lhe garante a unidade temática. Desses quatro elementos (autor, leitor, assunto, situação), dois se colocam em primeiro plano no texto argumentativo: o autor e o leitor. Nesse tipo de texto, o autor procura influenciar seu leitor, pretende fazer com que ele altere sua maneira de pensar ou de agir, procura persuadi-lo a aderir a um ponto de vista (assumir uma posição política, converter-se a uma religião, apoiar uma decisão) ou a tomar uma decisão (comprar um produto, votar em um candidato). Partimos da premissa de que é possível desenvolver um trabalho de leitura de textos centrado na observação sistemática dos esquemas de construção da argumentação. O material usado para isso são textos de opinião, publicados em revistas e jomais (editoriais, artigos de crítica e reivindicação, discursos políticos), ensaios e textos publicitários, material em que o autor assume em geral uma postura persuasiva face ao leitor. Da mesma maneira, é possivel desenvolver um conjunto de atividades de produção textual em que sejam criadas situaçōes que levem o aluno a assumir essa mesma posição face a seu possivel leitor: tentar persuadi-lo e buscar sua adesão, mediante o uso de uma argumentação construída conscientemente.

Uma primeira faceta da argumentação é seu lado lógico: argumentar exige um raciocínio consistente, coerente, com exposição organizada. Mas seria ingênuo trabalhar a argumentação observando simplesmente esse lado, uma vez que os leitores são sensiveis a motivaçōes diversas, não só à logicidade do raciocínio. Seus valores, crenças e desejos por vezes se sobrepõem à racionalidade. Uma argumentação que apele a essas motivações é às vezes mais eficaz que aquela pautada pela logicidade. Assim. é interessante distinguir na argu-

2 COSTA, Iara Bemquerer. O Texto em Uso: Roteiro para a Produçāo/Recepçāo de Textos na Universidade. Inédito. Curitiba, 1993. 
mentação, por um lado, seus aspectos lógicos, o uso de estratégias argumentativas centradas na racionalidade da argumentação; por outro lado, há argumentos que o autor usa a partir de estratégias conversacionais, discursivas, que levam em conta o conhecimento (imagem) do leitor. ${ }^{3}$ É interessante que se procure apontar para a diferença entre esses dois tipos de argumentos, não com o intuito de evitar que um deles apareça nos textos, ou de se fazer observações valorativas simplesmente a propósito de um e outro, mas para que as estratégias argumentativas sejam escolhidas conscientemente.

\section{Argumentação no texto: estratégias lógicas}

Pode-se em um momento inicial do trabalho sistemático com a argumentação focalizar seu lado lógico, o que pode ser feito a partir da exploração intuitiva dos esquemas de raciocínio subjacentes aos textos. Cabe aqui lembrar o princípio tão repetido no clássico livro de $\mathrm{Garcia}^{4}$ de que o aprendizado da escrita deve ser necessariamente acompanhado do correspondente desenvolvimento do raciocínio: não se aprende a escrever sem aprender a pensar.

Como uma preparação para a exposição clara e coerente de um raciocínio, é interessante usar como material de apoio, textos e jogos que explorem de forma lúdica a organização de argumentos. Um exemplo disso é o trecho a seguir, extraído do romance $O$ Pêndulo de Foucaut de Umberto Eco, em que dois personagens discutem a (in)capacidade de raciocinar de algumas pessoas:

"E o estúpido?"

"Ah. O estúpido não se engana de comportamento. Engana-se no raciocínio. É aquele que diz que todos os cães são animais domésticos e que todos os cães latem, mas que também os gatos são animais domésticos e que portanto latem. Ou antes, que todos os atenienses são mortais, todos os habitantes do Pireu são mortais, logo todos os habitantes do Pireu são atenienses." "O que é verdade."

"Sim, mas por acaso. O estúpido pode mesmo dizer uma coisa certa, mas por motivos errados."

"Pode-se dizer coisas erradas, basta que as razões sejam justas."

3 O conceito de imagem aqui é tomada de PÊCHEUX, M. Analyse Atutomatique du Discours. Paris : Dunod, 1969.

4 GARCIA, Othon M. Comunicação em Prosa Modema. 4.ed. Rio de Janeiro : Fundação Getúlio Vargas, 1976. 
"Por Deus. Para que então esforçar-se tanto para ser animais racionais?"

"Todos os grandes símios antropomorfos descendem de formas de vida inferiores, os homens descendem de formas de vida inferiores, logo todos os homens são grandes símios antropomorfos. "Essa é bem boa. Já estamos naquele limiar em que a gente suspeita de que algo não se encaixa, mas que nos requer certo trabalho para demonstrarmos o que é e por quê."

(Umberto Eco, O Péndulo de Foulcaut, p.67)

Nesse texto, Umberto Eco fornece elementos interessantes para um trabalho sobre a relevância de se operar com raciocínios consistentes. No diálogo entre seus personagens, coloca-se em foco o julgamento sobre a capacidade de raciocínio dos indivíduos, exemplificada através da construção de falsos silogismos. A leitura de um texto como esse permite colocar em evidência os conceitos de verdade das proposiçōes e validade do raciocínio. No primeiro falso silogismo adotado como exemplo de raciocínio "estúpido", é possivel evidenciar as seguintes proposições:

1. Os cães são animais domésticos. (Para todo $x$, se $x$ é um cão, então $\mathrm{x}$ é um animal doméstico)

2. Os gatos são animais domésticos. (Para todo $x$, se $x$ é um gato, então $\mathrm{x}$ é um animal doméstico)

3. Os cães latem. (Para todo $x$, se $x$ é um cão, então $x$ late)

4. Portanto: Os gatos latem. (Para todo $x$, se $x$ é um gato, então $x$ late)

A evidente falha no raciocínio está, em primeiro lugar, no uso de uma proposição falsa: "Os gatos latem." Ninguém se deixaria enganar por um argumento que chegue a uma conclusão obviamente falsa. Mas além da óbvia constatação de que não pode haver raciocínio válido que convença alguém de que gatos latem, é interessante examinar o esquema de raciocínio adotado. Para isso pode-se recorrer, intuitivamente ao conceito de conjunto, que qualquer aluno que tenha passado pelas séries iniciais do primeiro grau reconhece sem a menor dificuldade. Pode-se observar que os exemplos utilizados por Umberto Eco se baseiam na inclusão de conjuntos em outros conjuntos. Existe um conjunto de indivíduos agrupados pelo predicado de serem animais domésticos. Esse conjunto inclui dois outros: o dos indivíduos reunidos pela propriedade de serem cães e aqueles que têm em comum o fato de serem gatos. $O$ conjunto dos cães apresenta ainda a propriedade de latir, ou seja, está inserido no conjunto dos seres que têm a propriedade de latir. O erro do raciocínio está em estender ao conjunto dos gatos a propriedade de latir, por este conjunto ter em 
comum com o dos cães o fato de estarem ambos incluídos no conjunto dos animais domésticos. Nada autoriza essa inferência.

Um exame dos dois outros exemplos apresentados por Eco mostrará analogias interessantes com o raciocínio a propósito dos cães e gatos. No exemplo dos atenienses, há o complicador do uso de expressões que designam o mesmo conjunto de indivíduos: "atenienses" e "habitantes do Pireu" e de se ter um raciocínio invál ido construído com proposições verdadeiras. No exemplo dos "grandes símios antropomor fos" o uso de uma linguagem erudita pode criar no leitor uma atitude respeitosa face ao texto que lhe dificulte a imediata apreensão da fragilidade do raciocínio.

Outro caso de uso lúdico da argumentação muito interessante, como estratégia a ser adotada em aula é a solução de problemas de raciocínio que operem um conjunto restrito de informações. Para solucionar tais problemas, faz-se necessário formular hipóteses, relacionar as proposições entre si, avaliar soluções parciais. Por exemplo:

De três prisioneiros que estavam num certo cárcere, um tinha visão normal, o segundo era caolho c o terceiro era totalmente cego. Os três eram, pelo menos, de inteligência média. $O$ carcereiro disse aos prisioneiros que, de um jogo de três chapéus brancos e dois vermelhos, escolheria três e colocá-los-ia em suas cabeças. Cada um deles estava proibido de ver a cor do chapéu que tinha em sua própria cabeça. Reunindo-os, o carcereiro ofereceu a liberdade ao prisioneiro com visão normal, se fosse capaz de dizer a cor do chapéu que tinha na cabeça. $O$ prisioneiro confessou que não podia dizer. A seguir, o carcereiro ofereceu a liberdade ao prisioneiro que tinha um só olho, na condição de que dissesse a cor de seu chapéu. O caolho confessou que também não sabia dizê-lo. O carcereiro não se deu ao trabalho de fazer idêntica proposta ao prisioneiro cego, mas, a instância deste, concordou em dar-lhe a mesma oportunidade. O prisioneiro cego abriu, então, um amplo sorriso e disse:

"Não necessito da minha vista; pelo que meus amigos com olhos disseram, vejo, claramente, que o meu chapéu é...."

(Copi, I. Introdução à Lógica. S. Paulo : Mestre Jou, 1968. p. 43) 
O trabalho com problemas desse tipo tem dois objetivos: primeiramente, exercitar o raciocínio lógico; além disso, essas atividades permitem mostrar como é importante que a exposição seja feita passo a passo, sem que haja saltos na demonstraçāo. Esse princípio do encadeamento, sem saltos no raciocínio pode ser utilizado na avaliação da qualidade da argumentação de textos de opinião lidos e no planejamento da produção de textos argumentativos.

Os dois exemplos comentados acima são uma pequena amostra de um trabalho sistemático que se pode fazer com a argumentação. Em linhas gerais, o trabalho proposto inclui as etapas indicadas a seguir. Primeiramente, nas atividades de leitura de textos argumentativos, procura-se sempre identificar o esquema argumentativo utilizado pelo autor: qual é a tese apresentada no texto e quais os argumentos utilizados para a sustentação dessa tese. Paralelamente, nas atividades de produção de texto pode-se levar o aluno a elaborar esquemas de argumentação (formulação da tese e argumentos) como uma atividade de preparação para a escrita.

Além de fazer a identificação do esquema argumentativo dos textos lidos, é interessante que se proceda também uma avaliação da qualidade de cada argumento: se os dados, fatos, exemplos, etc., utilizados são verdadeiros, se podem ser confirmados quando se observa o universo a que se referem. Se cada argumento é relevante para a tese que o autor propõe. ${ }^{5}$ O mesmo esquema de avaliação da qualidade dos argumentos pode ser aplicado aos esquemas de elaboração de textos preparados pelo aluno, ou à (auto-) avaliação de seus trabalhos.

Um terceiro tipo de atividade na leitura de textos de opinião é a identificação dos esquemas de contra-argumentação presentes no texto: o reconhecimento dos casos em que se tem a apresentação e refutação de teses opostas à do autor. Para um trabalho sistemático com a refutação de teses, pode ser feito um trabalho específico de uso de esquemas básicos de refutação de teses, como sugerido por Vigner (1988). ${ }^{6}$

\section{Argumentação no texto: estratégias conversacionais}

Em boa parte dos textos produzidos, tendo em vista a persuasão do leitor, a escolha de argumentos não é centrada na sua articulação lógica. Um exemplo

5 GARCIA, op. cit. dá indicaçóes muito interessantes para a avaliação da qualidade da argumentaçào dos textos em seu capilulo sobre consistência dos argumentos.

6 VIGNER. Gerard. Técnicas de Aprendizagem da Argumentação Escrita. In : GALVES, C; ORLANDI, E. P. ; OTONI, P. O Terto : Escrito e Leitura. Campinas : Pontes, 1988. 
típico são os textos publicitários, outro, o discurso político. Nos textos publicitários, por exemplo, a maior parte da argumentação está centrada na sensibilidade do interlocutor a determinados elementos motivadores. Os leitores podem ser mais ou menos sensíveis a argumentos que façam referência a motivações situadas em vários campos: status, esporte, beleza, erotismo, humor, religião, nacionalismo, gastronomia, etc. A construção da argumentação nesse tipo de texto elege, em geral, um desses campos e procura escolher argumentos fortes dentro daquele campo. No texto de doutrinação política são adotados procedimentos semelhantes: para conseguir a adesão do interlocutor (possível eleitor), apela-se para os valores e crenças que se supõe serem importantes para o interlocutor, mais do que para a articulação lógica entre tese e argumentos.

$O$ uso de argumentos centrados no universo do leitor fica evidente no texto abaixo, assinado por Luís Fernando Veríssimo, que fez parte da campanha publicitária da cerveja Antárctica em 1993:

\section{Uma Paixão Nacional}

Ela disse "Você me ama mais do que tudo?" e ele disse "Amo". Ele disse "Paixão, paixão". E reforçou: "Mesmo".

Ela: "Mais do que tudo no mundo todo?"

Ele: "No mundo todo e fora dele".

Ela: "Não acredito".

Ele: "Faz um teste".

"Eu ou fios de ovos."

"Você, fácil."

"Daqueles com calda grossa, a gente chupa o fio e a calda escorre pelo queixo."

"Prefiro você."

"Futebol."

"Nem tem comparação."

"Você está caminhando, vem uma bola quicando, a garotada grita 'Devolve, tio!' e você domina, faz dezessete embaixadas e chuta com perfeição."

"Prefiro você.."

"Internacional e Milan em Tóquio pelo campeonato do mundo, passagem e entrada de graça."

"Você vai junto?"

"Não."

"Pela televisão se vê melhor."

"Faz muito calor. Aí chove, aí abre o sol, aí vem uma brisa fresca com aquele cheiro de terra molhada, aí toca uma música 
no rádio e é uma nova do Paulinho. É sexta-feira e a televisão anunciou um Hitchcock sem dublagem praquela noite, e o Itamar está dando certo."

"Você."

"Voltar à infância só pra poder pisar na lama com o pé descalço e sentir a lama fazer esquish entre os dedos."

"Você, longe."

"A Sharon Stone telefona e diz que é ela ou eu."

"Que dúvida. Você."

"Cheiro de livro novo. Solo de sax-alto. Criança distraida. Canetinha japonesa. Bateria de escola de samba. Lençol recémlavado. Hora no dentista cancelada. Filme com escadaria curva. Letra do Aldir Blanc. Pastel de rodoviária."

"Você, você, você, você, você, você, você, você, você e você, respectivamente."

"A Sharon Stone telefona de novo e diz que se você se livrar de mim ela já vem sem calcinha."

"Desligo o telefone."

"Fama e fortuna. A explicaçāo do universo e do mercado de commodities, com exclusividade. A vida eterna e um cartão de crédito que nunca expira."

"Prefiro você."

"Uma cerveja geladinha. A garrafa chega estalando. No copo, fica com um quarto de espuma firme. O resto é ela, só ela, dizendo 'vem'."

"Hmmm..."

"Como, 'hmmm'? Ela ou eu?"

Silêncio. Depois:

"Qual é a marca?"

"Seu cretino!"

(Folha de São Paulo, 22 jan. 1993).

Esse texto mostra a construção da argumentação típica do texto publicitário, com a peculiaridade de situar seus argumentos em vários campos, em vez de selecionar um campo apenas, como se tem na maioria dos textos desse tipo. Observe como se faz a construção dos argumentos. A partir da pergunta inicial da namorada - "Você me ama mais do que tudo?" - são selecionados sucessivamente campos em que a argumentação será construída. Dentro de cada campo, é escolhido algum objeto ou situação que tenha a possibilidade de representar o que há de melhor dentro daquele campo. Para cada escolha, recoloca-se a questão: "Eu ou ...?" Por exemplo, no campo da gastronomia, os fios de ovos representam o que há de melhor, argumento reforçado pela 
descrição de que não são quaisquer fios de ovos, mas "aqueles com calda grossa", que representariam o melhor entre os fios de ovos. No futebol, apresenta-se o que pode haver de melhor para o leitor: jogar bem ou assistir "Internacional e Milan em Tóquio pelo campeonato do mundo, passagem e entrada de graça".

Em textos cuja argumentação é construída a partir de estratégias conversacionais e não lógicas, é interessante que se faça um trabalho de reconhecimento das estratégias argumentativas adotadas, formulando-se esquemas análogos aos adotados na análise dos aspectos lógicos, e a seguir uma avaliação das razões que possam ter levado o autor à escolha de tais estratégias. A eficácia da argumentação escolhida também pode ser objeto de avaliação.

\section{A imagem do leitor}

No início deste texto chamou-se a atenção para o fato de o texto argumentativo colocar em primeiro plano a relação entre o autor e um possível leitor, e de se estabelecer entre ambos uma relação específica: o autor visa a adesão do leitor a seu ponto de vista. Nas atividades escolares de produção de texto, a relação autor/leitor confunde-se com a relação institucional aluno/professor. Essa relação dilui e dificulta a construção de textos argumentativos pelo aluno: como reflexo de uma relação tradicionalmente autoritária professor/aluno, este tende a não argumentar realmente quando tem como leitor o professor. A tendência nesse caso é que ele assuma como tese aquela que supõe seja a preferida pelo professor. Isso compromete toda a argumentação.

Nas atividades de produção de textos, é possível a adoção de estratégias que facilitem a construção de uma imagem de interlocutor diversa do professor. Para isso, um recurso possível é fazer com que esses textos sejam dirigidos a um interlocutor cujo ponto de vista sobre o tema seja apresentado ao aluno de alguma forma. Por exemplo, na produção de um texto de opinião sobre o tema do separatismo, o aluno pode tomar como interlocutor o autor de uma das seguintes cartas à Folha de S. Paulo:

O Brasil, como federação, é ingovernável, é um fracasso histórico: dividido em quatro ou cinco países, de homogeneidade cultural, social e econômica, o desenvolvimento poderá ser mais rápido, eficiente e justo, sem os entraves da atual federação (Carta do leitor C.T. de São Paulo-SP à Folha de S. Paulo, maio 1993). 
Se esse bando de vagabundos nāo tem o que fazer a não ser ficar pensando em separatismo, que venham aqui na minha cidade porque estou precisando de gente para trabalhar na minha empresa. Quem trabalha nāo tem tempo de ficar pensando nessa bobagem de separatismo (Carta do leitor L.G.A.P., de Pindamonhangaba- SP, à Folha de S. Paulo, maio 1993).

$\mathrm{Na}$ apresentação de trechos que ajudem na construção da imagem do interlocutor é interessante, sempre que possível, mostrar pontos de vista opostos, para que o aluno possa escolher aquele que the interessa questionar.

Vigner (1988) apresenta uma série de sugestōes de atividades para o treinamento da argumentação em que se explora a relação autor/leitor. Sugere que o aluno seja levado a assumir posturas diversas frente a leitores também diversos. A cada nova relação autor/leitor criada, a escolha dos argumentos em um texto precisa ser revista.

\title{
RESUMO
}

Discute-se neste artigo, inicialmente, a importância do desenvolvimento de um trabalho escolar sistemático com esquemas de argumentação como parte das atividades de produção/recepsão de textos. Aponta-se a seguir algumas estratégias voltadas para os aspectos lógicos e conversacionais da argumentação e para a formação de uma imagem do leitor que não se identifique com o professor.

Palavras-chave: Ensino de Língua Materna, Texto, Argumentação.

\begin{abstract}
At first present article discusses, the importance of the development of a systematic educational work including argumentation schemes among the activities devised for the production/reception of texts. Second, it suggests some strategies that focus on logical and conversational aspects of argumentation and on the building of the image of a reader who bears no resemblance to the teacher.
\end{abstract}




\section{REFERÊNCIAS BIBLIOGRÁFICAS}

COPI, Irving. Introdução à Lógica. São Paulo: Mestre Jou, 1968.

COSTA, Iara Bemquerer. O Texto em Uso: Roteiro para a Produção/Recepção de Textos na Universidade. Inédito. Curitiba, 1993.

FAVERO, Leonor Lopes. Coesão e Coerência Textuais. São Paulo: Ática, 1991.

GARCIA, Othon M. Comunicação em Prosa Moderna. 4. ed. Rio de Janeiro: Fundação Getúlio Vargas, 1976.

PÊCHEUX, M. Analyse Aluomatique du Discours. Paris: Dunod, 1969.

VIGNER, Gerard. Técnicas de Aprendizagem da Argumentação Escrita. In: GALVES, C; ORLANDI, E.P.; OTONI, P. O Texto: Escrita e Leitura. Campinas: Pontes, 1988. 